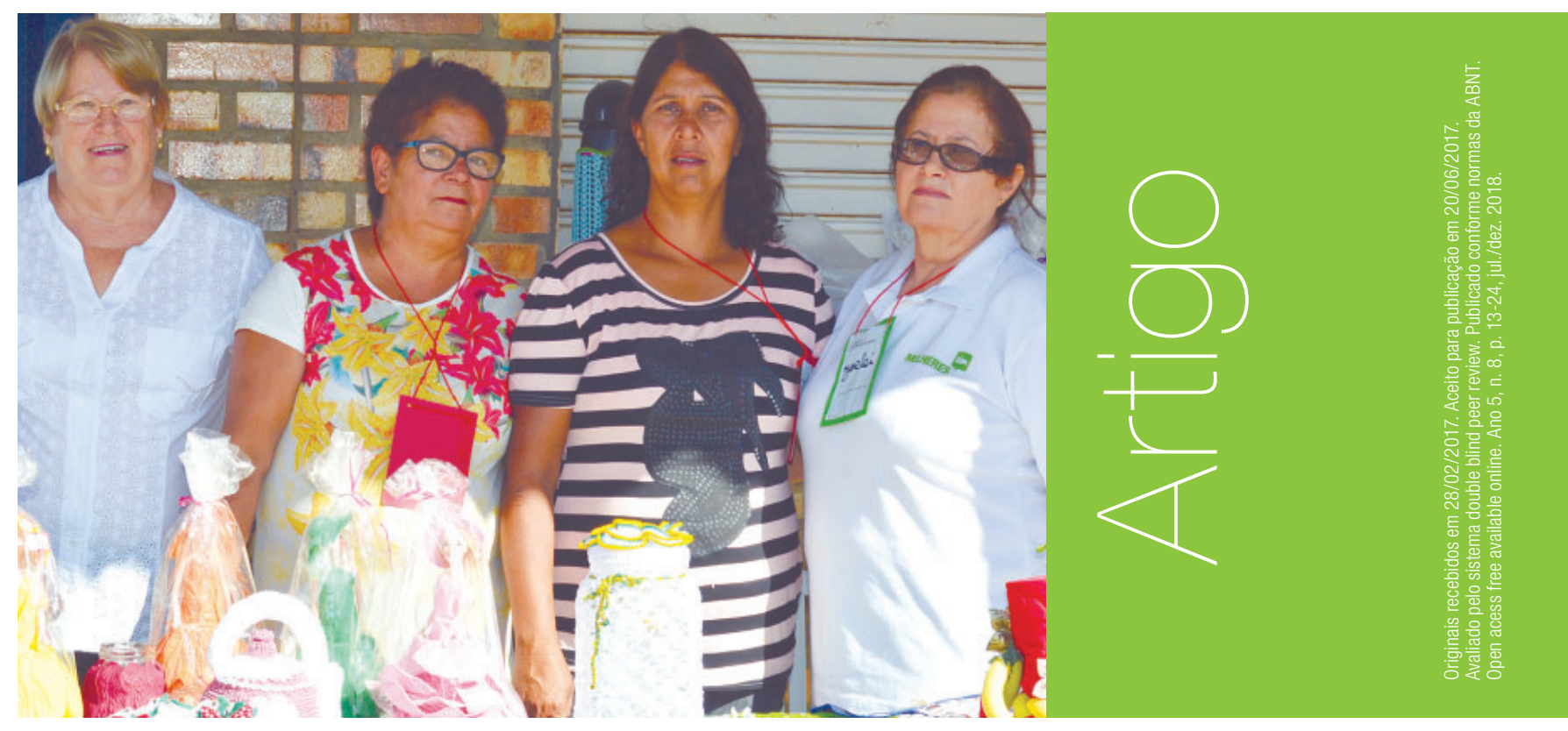

\title{
A experiência da $1^{a}$ edição do programa Mulheres Sim no IFSC - Câmpus Xanxerê
}

\author{
Jóice Konrad - joice.konrad@ifsc.edu.br \\ Giovana Bianca Darolt Hillesheim - giovana.bianca@ifsc.edu.br² \\ Guilherme Bruschi Frizzo - guilhermebruschi@hotmail.com³
}

\section{RESUMO}

0 presente trabalho trata-se de um estudo de caso, que tem como objetivo analisar o Programa Mulheres SIM realizado durante o segundo semestre de 2016 no IFSC Xanxerê. Foram adotados como procedimentos metodológicos: revisão bibliográfica que historiciza e fundamenta o programa, aplicação de questionários e realização de entrevistas com egressas. Concluise que, ao atender 25 mulheres, o programa oportunizou significativa contribuição na sua formação humana e profissional, instrumentalizando-as com novas vivências/conhecimentos e despertando sua atenção em relação aos cuidados com a saúde, seus direitos enquanto cidadãs, mulheres, mães e trabalhadoras.

\section{PLAVRAS-CHAVE}

Cidadania. Empoderamento feminino. Vulnerabilidade social.

\footnotetext{
1 Doutoranda em Geografia pela Universidade Estadual Paulista Júlio de Mesquita Filho - Câmpus Presidente Prudente, São Paulo e Professora do Instituto Federal de Santa Catarina - Câmpus Xanxerê, Santa Catarina;

2 Doutoranda em Artes Visuais pela Universidade Estadual de Santa Catarina - Câmpus Florianópolis, Santa Catarina e Professora do Instituto Federal de Santa Catarina - Câmpus Xanxerê, Santa Catarina;

3 Estudante do curso Técnico em Informática Integrado ao Ensino Médio do Instituto Federal de Santa Catarina Câmpus Xanxerê, Santa Catarina.
} 


\section{ABSTRACT}

The following work is a case study, which aims to review the "Programa Mulheres SIM" implemented during the second semester of 2016 at IFSC Xanxerê. To develop this work was adopted as methodological procedures: bibliographic review that historicizes and underpins the project, application of questionnaires and a personal interview with the graduates. It was concluded that, on attending 25 women, the program provided a significant opportunity in their human and professional formation, providing them new perceptions/knowledge and awaking their attention to health care, their rights as citizens, women, mothers and workers.

\section{KEYWORDS}

Citizenship. Female empowerment. Social vulnerability.

\section{Introdução}

0 Mulheres Sim é um programa do Instituto Federal de Santa Catarina (IFSC), vinculado à PróReitoria de Extensão e Relações Externas (Proex). Ele é estruturado por meio de quatro projetos de extensão: a) Curso de Formação Inicial e Continuada (FIC) em Educação e Gênero ou Geração de Renda, Tecnologia e Valorização do Trabalho Feminino, ambos os componentes curriculares dão sustentação para a construção de conhecimentos visando o exercício da cidadania, geração de renda e a melhoria da qualidade de vida; b) Feira de Economia Solidária, com finalidade pedagógica de incentivar a economia criativa, coletiva e a inclusão social; c) Ciclo de palestras e d) Acompanhamento das Egressas.

Trata-se de um programa de extensão de cunho social, sendo a extensão a responsável por interligar os demais pilares da instituição: 0 ensino e a pesquisa. Essa ligação visa levar à comunidade externa o conhecimento produzido no IFSC, correlacionando docentes, discentes, servidores e comunidade externa, potencializando o "alcance social à produção de conhecimento" científico (WITT; SOUZA, 2016). Os projetos de extensão também convidam a comunidade a repensar o seu entorno, identificar situações problemáticas e maneiras de resolvê-las. Nesse sentido, o Programa Mulheres SIM apropria-se dessa ligação visando a inclusão da mulher nas dimensões educacional, econômica, social e cultural da sociedade. Esse programa tem como enfoque a questão de gênero, buscando atender mulheres em vulnerabilidade social e sem escolaridade. Uma das possibilidades é a maior especificação do público-alvo, objetivando que o programa esteja intensamente conectado à realidade local.

A edição piloto aconteceu em 2014, englobando oito câmpus. Um deles foi o Câmpus Caçador, que voltou sua atenção para a população carcerária feminina do município. A proposta era "estimular nessas mulheres 0 afloramento das suas potencialidades individuais para geração de renda" (ULLRICH, 2016, p. ). Neste caso, assumiu-se uma responsabilidade dupla: preparar essas mulheres para um mercado de trabalho que não irá vê-las somente como mulheres (0 que, por si só, já é uma situação de vulnerabilidade), mas também como ex-carcerárias.

Apesar dos avanços sociais recentes, mulheres continuam a vivenciar histórias de vulnerabilidade e a protagonizar papéis considerados economicamente periféricos. Em Xanxerê, 15,34\% do total de mães/chefes de família são mulheres que não possuem ensino fundamental completo e possuem filhos pequenos (ATLAS DO DESENVOLVIMENTO HUMANO DO BRASIL, 2010). Quanto à renda e trabalho no município, $15,18 \%$ da população apresenta-se vulnerável à pobreza, aliando-se aos $27,11 \%$ da população de 18 anos ou mais que não tem ensino fundamental completo e possui ocupação informal. Diante dessa realidade, o Câmpus Xanxerê submeteu a proposta do projeto FIC Educação e Gênero ao Edital Proex - No 06/2016, tendo como objetivo oferecer oportunidades de reflexão e instrumentalização para que as mulheres em vulnerabilidade social tivessem acesso à formação profissional qualificada.

0 projeto foi selecionado e executado no segundo semestre de 2016. Tinha como públicoalvo mulheres com mais de 15 anos, preferencialmente jovens mães/chefes de família, sem escolaridade, moradoras dos bairros mais carentes do município, que desenvolviam atividades 
informais ou estavam desempregadas, que apresentavam-se em situação de vulnerabilidade social e que estavam/foram assistidas pelas unidades do Centro de Atendimento de Assistência Social do município.

0 presente artigo trata-se de um relato articulado a estudo de caso, que tem por objetivo analisar a primeira edição do Programa Mulheres SIM desenvolvido no IFSC - Câmpus Xanxerê.

\section{Metodologia}

Para o desenvolvimento deste artigo utilizamos como procedimentos metodológicos: revisão bibliográfica, aplicação de questionário e entrevistas com as participantes do programa. A fim de caracterizar o Programa Mulheres SIM, realizamos busca de material bibliográfico, como documentos, editais e artigos referentes ao desenvolvimento desse programa. Utilizamos ainda os resultados obtidos da aplicação dos questionários socioeconômicos e as entrevistas realizadas durante a execução do programa no câmpus. Os questionários foram aplicados com 14 alunas durante a aula inaugural, buscando caracterizar o perfil delas. Já as entrevistas, realizadas oralmente no último dia de atividade do programa e transcritas posteriormente, envolveram 20 alunas, tendo como objetivo a avaliação das atividades desenvolvidas. Diante disso, foi possível traçar as considerações que este artigo propôs inicialmente.

\section{Resultados e discussão}

A execução do Programa Mulheres SIM ocorreu de agosto a dezembro de 2016 com atividades todas as quartas-feiras e sextas-feiras, no período vespertino, totalizando 116 horas. 0 ingresso no programa ocorreu por meio de sorteio via Edital de Ingresso/DEING/PROEN. Foram ofertadas 30 vagas, tendo como pré-requisitos ser mulher e ter mais de 15 anos de idade. Entretanto, apenas 17 alunas matricularam-se, somadas às oito matrículas através das vagas remanescentes, totalizando 25 alunas. Com base nos dados do Registro Acadêmico, do total de matriculadas, duas alunas cancelaram e cinco alunas evadiram. Em um dos casos a evasão ocorreu após a aluna obter vaga de emprego; outras duas alunas não atingiram a frequência mínima de 75\%; as demais desistiram no decorrer do curso. Ao total, 18 alunas concluíram 0 curso com êxito, o que significa um satisfatório índice de conclusão de $72 \%$.

0 FIC implantado foi o de Educação e Gênero, com 96 horas dedicadas às unidades "Conhecimento histórico-cultural", "Saúde da mulher e da família", "Ética e cidadania", "Linguagens", "Informática", "Desenvolvimento social e sustentável", "Vivência matemática" e "Geração de Renda". As unidades curriculares trabalhadas tinham como objetivo fornecer às alunas subsídios para a construção de conhecimentos para o exercício da cidadania, melhoria da sua qualidade de vida e de sua família e desenvolvimento de habilidades manuais que permitissem 0 trabalho autônomo, inclusive no ambiente doméstico.

Com 0 auxílio de questionário traçamos 0 perfil socioeconômico das participantes. 0 grupo atendido era composto por mulheres brancas $(71 \%)$, residentes na área urbana de Xanxerê (86\%). Esperava-se atingir um número maior de mulheres entre os 15 e os 30 anos, o que não aconteceu: $57 \%$ da turma era formada por mulheres acima dos 40 anos. Isso não se mostrou um problema, apenas demandou uma adaptação dos métodos de ensino, de modo a tornar as aulas teóricas atrativas para este público.

Tabela 1 - Número de fillhos(as) das alunas do "Programa Mulheres SIM" - 2016/2

\begin{tabular}{cc}
\hline NÚMERO DE FILHOS(AS) & $\mathbf{N}^{\circ}$ DE ALUNAS \\
\hline Um & 5 \\
\hline Dois & 5 \\
\hline Três & 1 \\
\hline Quatro ou mais & 3
\end{tabular}

Fonte: Dados desta pesquisa. 
Com relação ao perfil de organização familiar, todas as 14 alunas tinham filhos(as), variando somente 0 número (Tabela 1), e 42,7\% delas não estavam em nenhum tipo de relação estável. Outro aspecto a se destacar é que 36\% das alunas relataram terem sofrido violência física, psicológica e/ou moral em algum momento de suas vidas. Esse dado mostra-se preocupante quando relacionado ao histórico de feminicídios no município. Um deles tendo acontecido no dia 20 de fevereiro de 2018, a vítima foi encontrada nua e com o rosto queimado (G1, 2018). Sendo assim, faz-se de extrema importância proporcionar-se mais espaços para discussões sobre esse e outros temas referentes à questão de gênero, visto que isso é um instrumento de conscientização contra a naturalização dessas práticas.

Os níveis de escolaridade (Tabela 2) foram os índices que mais variaram: 7,1\% da turma declarou-se como analfabeta e 71,5\% (11 alunas) não chegou a concluir o Ensino Médio. No entanto, foi possível identificar que $57 \%$ manifestava interesse em concluir seus estudos. Como nem todas as alunas eram alfabetizadas, as atividades desenvolvidas em sala de aula contaram com práticas pedagógicas diferenciadas, como trabalho expositivo, dinâmicas dialogadas com as atividades teóricas e atividades práticas; isso tornou ainda mais importante a valorização das experiências não-formais, adquiridas ao longo da vida das alunas.

Tabela 2 - Escolaridade das alunas do Programa Mulheres SIM - 2016/2

\begin{tabular}{|c|c|}
\hline NÍVEL DE ESCOLARIDADE & $N^{0}$ DE ALUNAS \\
\hline Nunca estudou & 1 \\
\hline Ensino Fundamental I ( $1^{\mathrm{a}}$ a $4^{\mathrm{a}}$ série) Incompleto & 3 \\
\hline Ensino Fundamental I ( $1^{\mathrm{a}}$ a $4^{\mathrm{a}}$ série) Completo & 1 \\
\hline Ensino Fundamental II ( $5^{\mathrm{a}}$ a $8^{\mathrm{a}}$ série) Incompleto & 2 \\
\hline Ensino Fundamental II ( $5^{\mathrm{a}}$ a $8^{\mathrm{a}}$ série) Completo & 2 \\
\hline Ensino Médio Incompleto & 2 \\
\hline Ensino Médio Completo & 2 \\
\hline Ensino Superior Completo & 1 \\
\hline
\end{tabular}

Fonte: Dados desta pesquisa.

Um exemplo de adequação metodológica é a aula retratada na Figura 1, da Unidade Curricular "Linguagens". 0 objetivo era que as alunas (divididas em grupos de cinco) pensassem em algum produto ou serviço com o qual já tivessem certa familiaridade (crochê, bordado, pintura, etc) e vendessem-no para a turma, utilizando os conceitos trabalhados na Unidade de "Linguagens" e "Geração de Renda". Essa atividade podia ser realizada de forma escrita ou oral considerando que muitas alunas não dominavam a escrita), tendo o auxílio de cartazes e demais recursos audiovisuais de sua escolha.

Figura 1: Aula da unidade curricular "Linguagens".

Fonte: Dados desta pesquisa.

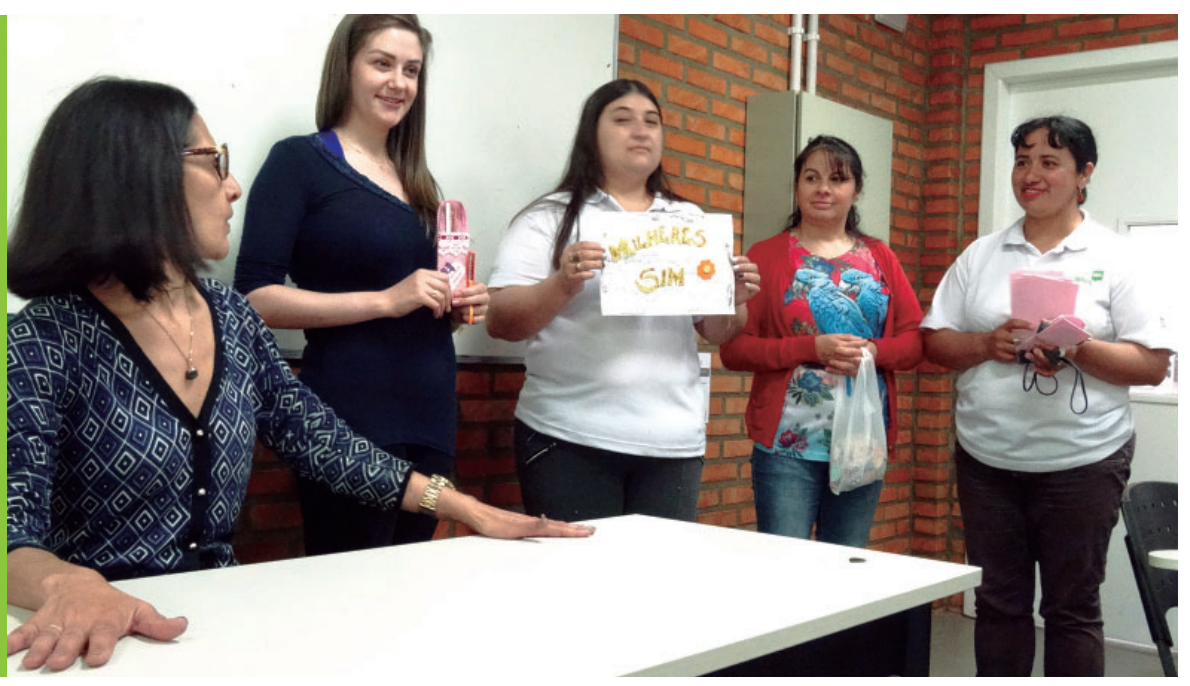


Além das aulas, as alunas participaram do projeto ciclo de palestras e oficinas, que complementou a sua formação. Foram 12 horas em que as alunas tiveram a oportunidade de aprofundar seus conhecimentos sobre questões pertinentes aos dias atuais, como a importância do pensamento pró-ativo e assuntos relacionados à educação de jovens e adultos. Este último ainda mais conectado com a realidade do programa, atuando como a motivação necessária para essa fase de novas experiências e aprendizados na vida das alunas. Também foram desenvolvidas oficinas de artesanato com a reutilização de materiais recicláveis, a fim de desenvolver habilidades manuais e aperfeiçoar os saberes sobre geração de renda e desenvolvimento sustentável.

A Feira de Economia Solidária (8 horas de duração), a segunda promovida no câmpus, tinha como propósito a exposição e a comercialização dos produtos confeccionados pelas integrantes durante a execução do Programa Mulheres SIM, valorizando a produção manual sem deixar de lado a preocupação ambiental. A presença de artesãs profissionais, discentes, docentes e servidores do IFSC, além da comunidade externa, fez com que a feira se transformasse em algo além do planejado: um ambiente de aprendizado, troca de conhecimentos e estabelecimento de novas amizades. Ela ainda contou com atividades culturais em parceria com os estudantes dos Cursos Técnicos em Alimentos/Informática Integrados ao Ensino Médio: apresentação musical, declamação de poemas e uma exposição fotográfica - resultado do projeto "Marílias", desenvolvido de forma paralela ao programa.

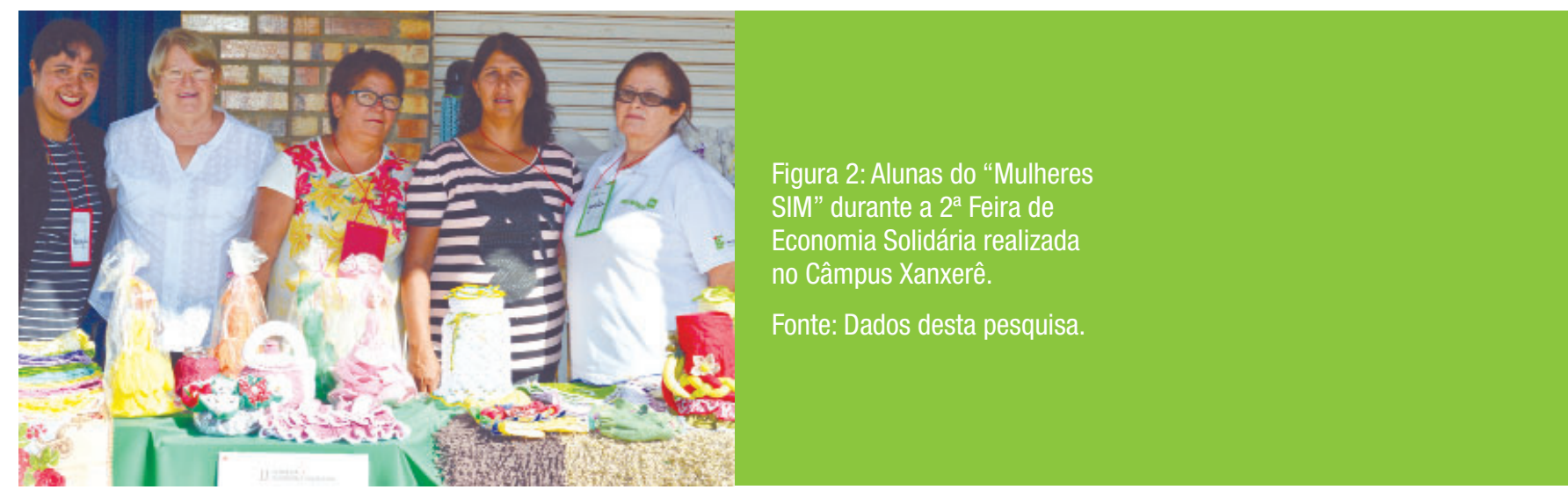

"Marílias" fotografou as alunas em interação com lenços de voil por elas decorados no desenrolar do componente curricular "Conhecimento histórico-cultural" (Figura 3). Neste âmbito, o projeto produziu dois ambientes de aprendizado. 0 primeiro, a socialização entre as alunas dos Cursos Técnicos em Alimentos/Informática Integrados ao Ensino Médio e as alunas do Mulheres SIM. Essa socialização foi capaz de tornar visíveis as "concepções de mundo distintas e que [...] reproduzem conflitos presentes na sociedade global, muitas vezes dificultando as relações interpessoais" (CALLIARI, 2017). Uma vez percebida, foi possível reverter essa diferença ideológica em algo positivo, capaz de proporcionar a troca de conhecimentos.

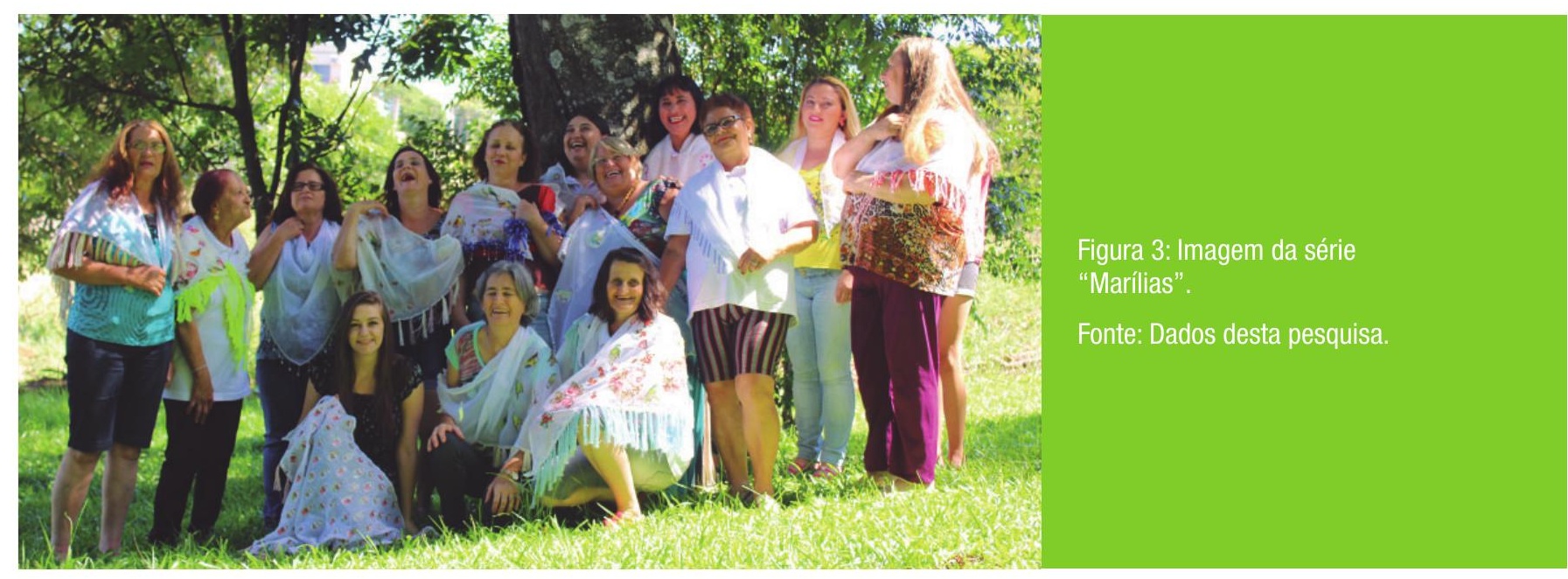


0 segundo, a produção dos lenços. Eles tinham por intuito resgatar fatos marcantes da vida de cada aluna, estando, portanto, carregados de material simbólico. A idade de cada mulher, por exemplo, estava simbolizada no número de franjas dos lenços. Além disso, o formato triangular dos mesmos foi utilizado como suporte para representar a infância, a juventude e a maturidade de cada mulher. Esse fazer estético foi alimentado por poesia e apresentação de personagens históricas femininas. Uma delas retirada do poema "Este é o lenço", da poetisa brasileira Cecília Meireles: Marília de Dirceu, alegoria que representa Maria Doroteia Joaquina de Seixas Brandão, personagem importante da Inconfidência Mineira. 0 lenço foi o companheiro de Maria (ou de Marilia) durante 0 exílio do companheiro, Tomás Antônio Gonzaga, exílio esse que impediu 0 casamento entre os dois. Para o Mulheres SIM o lenço assume um sentido mais otimista, de estimular um olhar para o passado a fim de perceber que cada uma das fases (infância, juventude e maturidade) tem igual importância na gênese do "eu" atual.

0 Programa mostrou-se muito significativo na vida dessas mulheres, à medida que possibilitou, sobretudo, 0 empoderamento ${ }^{4}$, a reflexão, 0 acesso aos direitos, à cidadania e a inclusão social e educacional das alunas. Para entrevistada 01 (2016), "foi muito bom, aprendi muita coisa e renovei o que eu sabia um pouco [...]". Além disso, o conhecimento sobre "direitos e deveres que a gente tem né, não exerce, e que é livre, né. A gente não é obrigada. Que nem eu, pensava assim quanta coisa, [...] fazia por medo, achava que complicava". Sobre as fragilidades encontradas no programa, a entrevistada 02 (2016) apontou que as disciplinas deveriam ter carga horária maior, possibilitando maior aprofundamento teórico. Outra questão levantada pela entrevistada 01 (2016) foi a necessidade de um espaço físico adequado para as atividades práticas. Inclusive, estes foram os aspectos sugeridos para melhorar nas próximas edições.

\section{Conclusões}

0 Programa Mulheres SIM contribuiu, a partir de diversos estímulos, à inclusão educacional, profissional e social de mulheres em situação de vulnerabilidade no município de Xanxerê. A avaliação das egressas (disponível nas entrevistas) demonstra uma grande aceitação do programa e das metodologias aplicadas. Isso demonstra que 0 trabalho desenvolvido superou suas expectativas iniciais; reforçando a necessidade de rever a estrutura física do Câmpus Xanxerê, problema apontado por grande parte dos discentes.

0 índice de evasão de 28\% não mostrou-se preocupante, considerando que, dessa porcentagem, $14 \%$ abandonou o curso por ter conseguido emprego e 92,8\% indicou interesse em continuar estudando no Instituto (segundo o questionário socioeconômico). É satisfatório que os apontamentos das alunas (principalmente os tópicos que mais as interessavam, compartilhados oralmente durante a aula inaugural) puderam ser utilizados para 0 melhor planejamento das edições futuras do programa no IFSC Câmpus Xanxerê. Ainda, segundo dados do Registro Acadêmico do Câmpus Xanxerê, 36\% das alunas do Mulheres SIM voltaram para o IFSC e fizeram outros cursos, transformando o programa numa porta de entrada, um divisor de águas na carreira profissional das egressas.

Os resultados positivos mostram a eficácia dos projetos de extensão de cunho social quando aplicados à realidade local. Por este motivo, faz-se necessário pesquisar e localizar os demais grupos enquadrados atualmente em vulnerabilidade social no município de Xanxerê, possibilitando pensar-se em outras alternativas e novas abordagens, mantendo um objetivo em mente: qualificar profissionalmente e reinserir essas pessoas na sociedade, nas esferas social, econômica, política e cultural.

\footnotetext{
4 O termo empoderamento é compreendido neste relato a partir da concepção de Paulo Freire. Empoderamento (no inglês empowerment) está relacionado ao ato comunitário de mapeamento e incorporação de valores comuns a determinados grupos, possibilitando que estes realizem transformações sociais. Trata-se de um termo bastante usado na Educação.
} 


\section{Referências}

ATLAS DO DESENVOLVIMENTO HUMANO NO BRASIL. Disponível em: <http://www. atlasbrasil.org.br/2013/pt/perfil_m/5359>. Acesso em: 25 jul. 2016.

CALIARI, Hellen Christine et al. Arte como mediadora de conflitos geracionais. 2017. Disponível em: <https://drive.google.com/file/d/OB2GxHiEWdveTYml2Ym1qMnNzOWs/view>. Acesso em: 28 fev. 2018.

ENTREVISTADA 01. Aluna do Programa Mulheres Sim - IFSC Xanxerê. Xanxerê-SC, 04 de dezembro de 2016. Entrevista concedida a Jóice Konrad.

ENTREVISTADA 02. Aluna do Programa Mulheres Sim - IFSC Xanxerê. Xanxerê-SC, 04 de dezembro de 2016. Entrevista concedida a Jóice Konrad.

FREIRE, P. Educação como prática da liberdade. Rio de Janeiro: Paz e Terra, 1967.

G1. Mulher é encontrada morta e sem roupas em mata de Xanxerê. Disponivel em: $<$ https://g1.globo.com/sc/santa-catarina/noticia/mulher-e-encontrada-morta-e-sem-roupasem-mata-de-xanxere.ghtml>. Acesso em: 28 fev. 2018.

MEIRELES, C. Este é o Lenço. In: Romanceiro da Inconfidência. Rio de Janeiro: Nova Fronteira, 1989.

SENAC MINAS GERAIS. Maria Doroteia Joaquina de Seixas. Disponível em: <http:// www.descubraminas.com.br/Turismo/DestinoAtrativoPagina.aspx?cod_destino=2\&cod_ atrativo=474\&cod_pgi=1070>. Acesso em: 28 fev. 2018.

ULLRICH, Danielle Regina. A construção de saberes no cárcere: a experiência do Programa Mulheres SIM no Presídio Regional de Caçador. NAU Social, v. 7, p. 23-30, 2016. Disponível em <http://www.periodicos.adm.ufba.br/index.php/rs/article/view/586> Acesso em 23 dez. 2016

WITT, Ania Tamilis da Silva; SOUZA, Paula Clarissa de. Programa de extensão Mulheres SIM: um estudo sobre suas alunas e sua efetividade nos câmpus. Caminho Aberto - Revista de Extensão do IFSC, ano 3, no 4, julho 2016 p.71-83 Disponível em < https://periodicos.ffsc. edu.br/index.php/caminhoaberto/article/view/1822> Acesso em: 23 dez. 2016. 